\title{
Distribuição de agregados e carbono orgânico em um Argissolo Amarelo distrocoeso em diferentes manejos ${ }^{1}$
}

\author{
Veronildo S. Oliveira², Mário M. Rolim², Romero F. B. Vasconcelos ${ }^{2} \&$ Elvira M. R. Pedrosa ${ }^{2}$
}

\section{RESU MO}

O objetivo principal deste estudo foi avaliar a estabilidade e a distribuição de agregados em um Argissolo Amarelo distrocoeso comparando-se os valores de uma área de mata nativa (MA), com três áreas cultivadas com cana-de-açúcar sendo uma sem irrigação (MSI), uma com irrigação $(\mathrm{MCl})$ e outra sob fertirrigação com vinhaça (MCV). O solo das três áreas cultivadas foi submetido ao mesmo tipo de preparo: gradagem pesada, gradagem leve e subsolagem. Amostras de solo com estrutura indeformada na área de mata e de cada área cultivada foram coletadas para determinação da estabilidade de agregados, expressa pelo diâmetro médio ponderado (DMP), índice de estabilidade de agregados (IEA), módulo de finura (MF), porcentagem de agregados estáveis em água com diâmetros maiores que 2,0 mm (AGRI) e valores de carbono total. Os distintos tipos de manejo do solo com cana-de-açúcar promoveram perda da estabilidade de agregados com o aumento da profundidade. A estabilidade de agregados foi reduzida em relação à mata nativa na sequência: $M A>M C V>M C I>M S I$. Registraram-se, na área sem irrigação (MSI) os menores índices de agregação, em que na submetida a fertirrigação com vinhaça (MCV) os valores foram semelhantes aos da área de mata nativa apresentando maior índice de estabilidade de agregados em água. Correlações significativas e positivas foram obtidas entre carbono orgânico total e os índices de agregação do solo (DMP > AGRI > MF > IEA) sob diferentes situações de manejo.

Palavras-chave: manejo do solo, insumo orgânico, vinhaça no solo

\section{Distribution of aggregates and organic carbon in an Ultisol submitted to different managements}

\begin{abstract}
The main objective of this study was to evaluate the stability and aggregate distribution of an Ultisol submitted to different management systems under sugarcane cultivation. Evaluated areas consisted of native forest (MA) and sugarcane managed areas with irrigation $(\mathrm{MCl})$, vinasse irrigation $(\mathrm{MCV})$ and without irrigation (MSI). Management of the areas followed the same conventional preparation: heavy and light harrowing and subsoiling. Undeformed soil samples were collected along the lines of the crop and in native forest to determine aggregate stability, expressed by the average weighted diameter (DMP), aggregate stability index (IEA), module of thinness (MF), percentage of stable aggregate in water larger than 2.0 $\mathrm{mm}$ (AGRI) and total organic carbon. The distinct kinds of soil management on sugarcane promoted decrease in aggregate stability as soil depth increased. In relation to native forest, aggregate stability reduced in the sequence $\mathrm{MA}>\mathrm{MCV}>\mathrm{MCl}>\mathrm{MSI}$. MSI showed the lowest aggregation indexes, in contrast to MCV data which closely linked with MA data and presented the best aggregate stability index in water. Significant and positive correlations were obtained between total organic carbon and stability indexes studied (DMP > AGRI > MF > IEA) under different management situations.
\end{abstract}

Key words: soil, aggregate stability, correlations, residue use

Parte da Tese de Doutorado do primeiro autor, UFRPE

DTR /UFRPE. Rua Dom Manoel de Medeiros s/n, Dois Irmãos, CEP 52171-900, Recife, PE. Fone: (81) 3320-6276. E-mail: verofat@dtr.ufrpe.br; rolim@dtr.ufrpe.br; romerofalcao@hotmail.com; elvira.pedrosa@dtr.ufrpe.br 


\section{INTRODUÇÃO}

A degradação do solo e do meio-ambiente tem despertado atenção do mundo inteiro. Neste sentido, a União Européia elegeu a compactação como uma das principais causas da degradação dos solos (COM, 2002); deste modo, se reveste de importância a identificação dos fatores que podem degradar o solo se refletindo na perda de conservação e da sustentabilidade das atividades agrícolas; assim, as forças externas que, de forma direta, promovem a compactação do solo, comprometem a estabilidade dos agregados (Soane, 1990; Baumgarti \& Horn, 1991). A formação e a estabilidade dos agregados são resultado da interação entre os processos físicos, químicos e biológicos no solo (Tisdall \& Oades, 1982).

Alterações na estrutura do solo desestabilizam o arranjo das partículas e, consequentemente, na distribuição de poros, comprometendo a disponibilidade de ar e água e o desenvolvimento do sistema radicular das plantas, além de aumentar a resistência mecânica do solo à penetração e ao manejo. A manutenção de um bom estado de agregação e estabilidade que preconizam a estrutura adequada do solo é condição primordial para obtenção de produtividades agrícolas com viabilidade econômica (Corrêa, 2002).

A estrutura do solo está relacionada com a infiltração e retenção de água, difusão do ar, com a temperatura do solo, e com o sistema radicular das plantas. Deste modo, quando a infiltração de água é baixa ou diminui em função do manejo o solo se torna mais suscetível ao processo de erosão, fenômeno este mais acentuado quando o solo é submetido aos sistemas de manejo que adotam revolvimento intensivo com baixas taxas de adição de resíduos orgânicos (restos de cultura, raízes, exsudações) afetando o teor de matéria orgânica do solo, principal agente de formação e estabilização dos agregados (Tisdall \& Oades, 1982).

O uso intensivo do solo, aliado ao manejo contínuo ou impróprio às suas condições físicas, concorre para o depauperamento de seus atributos físicos, com consequências drásticas para a estruturação (Olszevski et al., 2004). Do ponto de vista agronômico, a estrutura está relacionada ao arranjo das partículas, agregados e poros (Fageria \& Stone, 2006). Os agregados se formam pela ação de substâncias que promovem o contato ou união entre as partículas, denominadas agentes cimentantes, que podem ser compostos por materiais orgânicos, óxidos de ferro e de alumínio, carbonatos ou, principalmente, sílica e argila (Silva \& Mielniczuk, 1998).

O uso e o manejo conjugados ao tempo de utilização tendem a ocasionar perda da estrutura original do solo pelo fracionamento dos agregados maiores em unidades menores, com consequente redução dos macroporos e aumento de microporos e densidade (Carpenedo \& Mielniczuk, 1990). Sistemas de manejo com revolvimento em área total são os que mais degradam o solo fisicamente, em virtude de afetarem o teor de matéria orgânica, principal agente de formação e estabilização dos agregados (Silva \& Mielniczuk, 1998; Albuquerque et al., 2001).

Os agregados são classificados de acordo com o tamanho, em macroagregados, quando superiores a $250 \mu \mathrm{m}$, e microagregados aqueles inferiores a $250 \mu \mathrm{m}$ (Tisdall \& Oades,
1982). Os macroagregados são mais susceptíveis aos danos mecânicos por serem menos estáveis, razão da necessidade de sua preservação (Cambardella \& Elliot, 1993).

Os valores de microporosidade e densidade de um Argissolo Amarelo distrocoeso abrupto fragipânico de Alagoas sob cultivo contínuo com cana-de-açúcar, durante 30 anos, foram marcadamente elevados em relação ao solo de mata nativa (Maia \& Ribeiro, 2004). Para os autores ocorreu aumento de compactação nos horizontes $\mathrm{Ap}$ e $\mathrm{AB}$, referentes às camadas de 0 a 18 e de 18 a $34 \mathrm{~cm}$; verificaram-se, também, que nas faixas inferiores a $35 \mathrm{~cm}$ o maior valor da densidade do solo foi no perfil da mata nativa, demonstrando trata-se de adensamento pedogenético, característica dos Latossolos e Argissolos dos tabuleiros costeiros de Alagoas. A densidade dos horizontes coesos varia na faixa de 1,5 a $1,8 \mathrm{~kg} \mathrm{~m}^{-3}$, enquanto nos horizontes superficiais se situa na amplitude de 1,2 a $1,4 \mathrm{~kg} \mathrm{~m}^{-3}$, no solo de mata nativa (Araújo Filho et al., 2001).

Segundo Six et al. (1999) existe uma relação causa-efeito entre os agregados e a matéria orgânica do solo, razão por que a quebra dos agregados pela ação mecânica das máquinas e implementos agrícolas expõe a matéria orgânica à atividade microbiana, com redução do seu conteúdo no solo (Costa et al., 2004).

Diversos trabalhos apresentam dados evidenciando que o uso intensivo do solo agrícola promove diminuição da quantidade de agregados maiores que 2,0 mm. Neste sentido, Márquez et al. (2004) postulam que a qualidade do solo pode ser avaliada por meio da porcentagem de agregados estáveis.

O presente trabalho propõe avaliar a estabilidade de agregados de um Argissolo Amarelo Distrocoeso latossólico em uma área de mata nativa e três áreas sob diferentes sistemas de manejo com cana-de-açúcar.

\section{MATERIAL E MÉTODOS}

O experimento foi conduzido em um Argissolo Amarelo Distrocoeso latossólico, textura média/argilosa fase floresta subperenifólia, relevo plano (EMBRAPA, 2006), em área da Usina Triunfo, localizada entre os paralelos $9^{\circ} 40^{\prime} 47^{\prime \prime} \mathrm{e}$ $9^{\circ} 42$ ' 30" S e nos meridianos $36^{\circ} 08^{\prime} 12^{\prime \prime}$ e $36^{\circ} 05^{\prime} 03$ " W, no município da Boca da Mata, AL. O clima da região é do tipo As (Köppen), tropical com chuva no inverno, e precipitação média anual de $1200 \mathrm{~mm}$.

Quatro situações distintas de uso do solo foram escolhidas: uma coberta por vegetação nativa (floresta subperenifólia) MA - mata e outras três cultivadas continuamente com cana-de-açúcar, MSI - manejo sem irrigação; MCI - manejo com irrigação e MCV - manejo da fertirrigação com vinhaça. A área em manejo sem irrigação, cultivo de sequeiro, não recebe qualquer irrigação ou fertirrigação, há mais de 30 anos de exploração. Aplicou-se na área irrigada, uma lâmina de $120 \mathrm{~mm}$ de água durante o ciclo da cultura, através de aspersor tipo canhão, com vazão de $100 \mathrm{~m}^{3} \mathrm{~h}^{-1}$, mais de 25 anos, enquanto na área com fertirrigação são aplicados $500 \mathrm{~m}^{3}$ de vinhaça diluída anualmente, através de aspersão com $150 \mathrm{~m}^{3} \mathrm{~h}^{-1}$ de vazão, há mais de 25 anos. 
O preparo do solo das áreas cultivadas sempre foi feito com gradagem pesada, seguida de gradagem leve, precedida de subsolagem com implemento de hastes parabólicas, trabalhando a $40 \mathrm{~cm}$ de profundidade. Esta prática visa quebrar a camada compactada que está sempre associada à influência do processo de gênese desse solo, com posterior sulcagem a $25 \mathrm{~cm}$ de profundidade; a adubação e o plantio foram realizados manualmente. Algumas características do solo se encontram indicadas na Tabela 1.

Tabela 1. Análise granulométrica e pH do Argissolo Amarelo Distrocoeso, em diferentes sistemas de manejo e profundidades em cultivo de cana-de-açúcar

\begin{tabular}{|c|c|c|c|c|}
\hline \multirow{3}{*}{$\begin{array}{l}\text { Prof } \\
(\mathrm{cm})\end{array}$} & \multicolumn{4}{|c|}{ Granulometria } \\
\hline & Areia & Silte & Argila & \multirow{2}{*}{$\mathrm{pH}$} \\
\hline & \multicolumn{3}{|c|}{$\mathrm{g} \mathrm{kg}^{-1}$} & \\
\hline \multicolumn{5}{|c|}{ Mata nativa (MA) } \\
\hline $0-20$ & 727,0 & 57,0 & 216,0 & 4,8 \\
\hline $20-40$ & 661,7 & 60,6 & 277,7 & 4,8 \\
\hline $40-60$ & 564,0 & 36,0 & 400,0 & 5,4 \\
\hline \multicolumn{5}{|c|}{ Manejo sem irrigação (MSI) } \\
\hline $0-20$ & 677,5 & 80,3 & 242,2 & 4,8 \\
\hline $20-40$ & 581,2 & 47,8 & 371,0 & 4,9 \\
\hline $40-60$ & 550,7 & 42,8 & 406,5 & 4,7 \\
\hline \multicolumn{5}{|c|}{ Manejo com irrigação (MCI) } \\
\hline $0-20$ & 701,4 & 53,9 & 244,7 & 4,9 \\
\hline $20-40$ & 668,6 & 67,2 & 264,2 & 4,6 \\
\hline $40-60$ & 606,2 & 40,3 & 353,5 & 4,4 \\
\hline \multicolumn{5}{|c|}{ Manejo com fertirrigação (MCV) } \\
\hline $0-20$ & 722,5 & 64,3 & 213,2 & 6,2 \\
\hline $20-40$ & 751,2 & 18,8 & 230,0 & 5,7 \\
\hline $40-60$ & 674,2 & 20,3 & 305,5 & 5,3 \\
\hline
\end{tabular}

Em março de 2006, ainda no período da estiagem, foram coletadas, nos locais sorteados das quatro áreas em estudo, amostras simples de solo com estrutura indeformada de solo, nas profundidades de 0-20, 20-40 e 40-60 cm, em três repetições. Nas áreas cultivadas as amostras foram coletadas nas entre linhas da cultura da cana-de-açúcar. Três trincheiras por parcela em cada talhão foram abertas, retirando-se uma amostra por profundidade de cada trincheira. No Laboratório uma parcela das amostras foi utilizada para as análises de estabilidade de agregados e outra colocada para secar ao ar, durante $72 \mathrm{~h}$ e posteriormente destorroada e passada na peneira de 2,00 mm para análise de carbono orgânico total (COT) e análise granulométrica.

As frações granulométricas de areia, silte e argila foram quantificadas pelo método do densímetro de Boyoucos, usando-se um agitador mecânico com dispersante físico, durante $15 \mathrm{~min}$ e, como dispersante químico, usaram $25 \mathrm{~mL}$ de hexametafosfato de sódio (Calgon), enquanto a matéria orgânica das amostras de solo foi determinada de acordo com EMBRAPA (1997).

A estabilidade de agregados foi avaliada pelo método descrito por Kemper \& Chepil (1965), através de peneiramento em água, após pré-umedecimento lento dos agregados, por capilaridade. Para a determinação da agregação do solo, $100 \mathrm{~g}$ foram umedecidos e, posteriormente, colocados em dois conjuntos de cinco peneiras com malhas de 3,35; 2,00; 1,00; 0,50 e $0,25 \mathrm{~mm}$, respectivamente; em seguida, os conjuntos de peneira foram submetidos a agitação vertical (42 ciclos por min) durante $10 \mathrm{~min}$, em recipiente com água. O material retido em cada peneira foi colocado em recipientes para secagem em estufa a $105{ }^{\circ} \mathrm{C}$, durante $24 \mathrm{~h}$. Os valores de diâmetro médio ponderado (DMP) (Kemper \& Rosenau, 1986), índice de estabilidade de agregados (IEA) e o módulo de finura (Freire \& Piedade Jr., 1979) e o AGRI, somatório dos porcentuais, a 2,00 $\mathrm{mm}$ (Wendling et al., 2005) foram determinados segundo fórmulas a seguir:

$$
\begin{aligned}
\mathrm{DMP}= & \sum_{\mathrm{i}=1}^{\mathrm{n}}(\mathrm{cp} \times \mathrm{p}) \\
\mathrm{IEA}= & {[(\mathrm{MS}-\mathrm{wp} 0,25-\text { areia }) /(\mathrm{MS}-\text { areia })] \times 100 } \\
\mathrm{MF}= & \sum[(4,76-3,25)+(3,25-2,0)+(2,0-1,0)+(1,0-0,50) \\
& +(0,5-0,25)+(<0,25)] / 100
\end{aligned}
$$

AGRI $=$ wi $>2 \times 100$

donde,

$\mathrm{cp}$ - é igual ao centro de cada classe de peneira e p, o peso seco da amostra, em porcentagem

Ms - massa seca da amostra, g

wp0,25 - massa dos agregados da classe $<0,25 \mathrm{~mm}$, g

MF - módulo de finura dos agregados

$\Sigma$ - somatório da porcentagem acumulada de agregados em cada classe

wi $>2$ - representa a proporção de agregados $>2,00 \mathrm{~mm}$

$\mathrm{O}$ delineamento experimental utilizado foi inteiramente casualizado, incluindo-se a profundidade como subfator. Os resultados foram submetidos a análise de variância e as diferenças entre médias comparadas pelo teste de Tukey, a 5\% de probabilidade, utilizando-se o programa SAEG (2005). Para o estudo de correlações entre as diversas variáveis efetuou-se o ajuste de equações, a nível de $5 \%$ ou $1 \%$ de significância.

\section{RESULTADOS E DISCUSSÃO}

Os teores de carbono orgânico total foram mais baixos nas áreas sob cultivo, independentemente do manejo, em relação ao solo de mata nativa. Na profundidade de 0-20 o COT decresceu 52,42 e 39,41\% nos manejos MSI e MCI, respectivamente, comparado ao do solo de MA. Por outro lado, a menor redução de $18,94 \%$ foi registrada no solo ferirrigado com vinhaça; possivelmente, este menor declínio se deva à adição de matéria orgânica ao solo sob a aplicação do insumo orgânico. Em uma avaliação geral da Tabela 2 percebe-se, independentemente do manejo, que o cultivo contínuo reduz o teor de carbono orgânico do solo; verifica-se, porém o efeito benéfico da vinhaça em dotar o solo de maior conteúdo de carbono.

Os valores médios do DMP, obtidos por peneiramento via úmida, do IEA, MF e AGRI apresentaram média geral de $1,44 \mathrm{~mm}, 72,65,2,31$ e 29,55\%, respectivamente (Tabela 3). 
Tabela 2. Carbono orgânico total (COT) de um Argissolo Amarelo Distrocoeso, em diferentes sistemas de manejo e profundidades sob cultivo de cana-de-açúcar*

\begin{tabular}{rcccc}
\hline $\begin{array}{r}\text { Prof. } \\
\text { (cm) }\end{array}$ & \multicolumn{4}{c}{ COT $\left.\mathbf{~ ( g ~ k g - 1 ~}^{-1}\right)^{* *}$} \\
\cline { 2 - 5 } & MA & MSI & MCl & MCV \\
$0-20$ & $32,73 \mathrm{Aa}$ & $15,57 \mathrm{Ca}$ & $19,83 \mathrm{Ca}$ & $26,53 \mathrm{Ba}$ \\
$20-40$ & $27,47 \mathrm{Ab}$ & $10,87 \mathrm{Cab}$ & $13,60 \mathrm{BCb}$ & $16,77 \mathrm{Bb}$ \\
$40-60$ & $18,43 \mathrm{AC}$ & $0,8 \mathrm{~B} \mathrm{Cb}$ & $10,60 \mathrm{Bb}$ & $14,93 \mathrm{Ab}$ \\
\hline
\end{tabular}

* MA - Mata nativa; MSI - Manejo sem irrigação; $\mathrm{MCl}$ - Manejo com irrigação; MCV - Manejo com vinhaça

** Letras maiúsculas comparam diferenças entre os manejos e minúsculas entre profundidade do solo, a nível de $5 \%$ de probabilidade pelo teste de Tukey. Média de três repetições

A interação tipo manejo $\mathrm{x}$ profundidade do solo não influenciou nos valores do diâmetro médio ponderado dentre as distintas áreas significativas entre o DMP nos diversos manejos, nas profundidades estudadas. Entretanto, se constata pela comparação entre os manejos, superioridade significativa dos valores do DMP no solo de mata em relação aos demais. Os resultados indicam que, ao longo do tempo, os manejos contribuem para a degradação dos solos. Os dados obtidos estão em acordo com os apresentados por Silva et al. (2006), que trabalharam em condições semelhantes e observaram que tanto o manejo de sequeiro quanto o irrigado se mostraram mais susceptíveis a desagregação, apresentando valores de DMP menores que os agregados do solo de mata.

Tabela 3. Diâmetro médio ponderado, índice de estabilidade de agregados, módulo de finura e Agri, determinados nos quatro sistemas de manejo nas três profundidades estudadas*

\begin{tabular}{|c|c|c|c|c|}
\hline \multirow{2}{*}{$\begin{array}{l}\text { Sistema de } \\
\text { Manejo }\end{array}$} & \multicolumn{3}{|c|}{ Profundidade $(\mathrm{cm})^{* *}$} & \multirow{2}{*}{ Média } \\
\hline & $0-20$ & $20-40$ & $40-60$ & \\
\hline \multicolumn{5}{|c|}{ Diâmetro Médio Ponderado (mm) } \\
\hline MA & 1,99 & 1,75 & 1,49 & $1,74 \mathrm{~A}$ \\
\hline MSI & 1,29 & 1,28 & 1,17 & $1,25 \mathrm{C}$ \\
\hline $\mathrm{MCl}$ & 1,41 & 1,28 & 1,16 & $1,28 \mathrm{C}$ \\
\hline MCV & 1,58 & 1,50 & 1,42 & $1,49 \mathrm{~B}$ \\
\hline Média & $1,56 \mathrm{a}$ & $1,45 a b$ & $1,31 \mathrm{~b}$ & 1,44 \\
\hline \multicolumn{5}{|c|}{ Índice de Estabilidade de Agregados (\%) } \\
\hline MA & 82,54 & 73,90 & 73,81 & $76,75 \mathrm{~A}$ \\
\hline MSI & 74,32 & 76,47 & 76,27 & $75,69 \mathrm{~A}$ \\
\hline $\mathrm{MCl}$ & 65,24 & 73,73 & 67,31 & $68,76 \mathrm{~A}$ \\
\hline MCV & 62,56 & 73,95 & 71,76 & $69,42 \mathrm{~A}$ \\
\hline Média & $71,16 \mathrm{a}$ & $74,51 a$ & $72,29 a$ & 72,65 \\
\hline \multicolumn{5}{|c|}{ Módulo de Finura dos Agregados } \\
\hline MA & 2,98 & 2,67 & 2,40 & $2,68 \mathrm{~A}$ \\
\hline MSI & 2,19 & 2,21 & 1,93 & $2,11 \mathrm{~B}$ \\
\hline $\mathrm{MCl}$ & 2,27 & 2,02 & 1,84 & $2,05 \mathrm{~B}$ \\
\hline MCV & 2,45 & 2,36 & 2,36 & $2,39 A B$ \\
\hline Média & $3,07 \mathrm{a}$ & $2,86 a b$ & $2,67 \mathrm{~b}$ & 2,31 \\
\hline \multicolumn{5}{|c|}{ AGRI (\%) } \\
\hline MA & 46,75 & 42,26 & 33,03 & $40,68 \mathrm{~A}$ \\
\hline MSI & 23,33 & 20,35 & 20,38 & $21,35 \mathrm{C}$ \\
\hline $\mathrm{MCl}$ & 27,83 & 26,15 & 21,03 & $25,00 \mathrm{C}$ \\
\hline MCV & 32,64 & 33,09 & 27,81 & 31,18 B \\
\hline Média & $32,64 a$ & $30,46 a$ & $25,56 \mathrm{~b}$ & 29,55 \\
\hline
\end{tabular}

* MA - Mata nativa; MSI - Manejo sem irrigação; MCl - Manejo com irrigação; MCV - Manejo com vinhaça

** Letras maiúsculas comparam diferenças entre os manejos e minúsculas entre profundidade do solo, a nível de $5 \%$ de probabilidade pelo teste de Tukey. Média de três repetições
De maneira geral, o DMP decresceu na seguinte ordem: MA > MCV < MCI < MSI, com valores de 1,74; 1,49; 1,28 e $1,25 \mathrm{~mm}$, respectivamente. Observou-se maior estabilidade de agregados na profundidade de $0-20 \mathrm{~cm}$. O teste de Tukey aplicado às médias do DMP nas três profundidades para os solos sob diferentes manejos apresentou significância estatística quando comparado com as primeiras $(0-20 \mathrm{~cm})$ e terceira $(40-60 \mathrm{~cm})$ profundidades; desta forma, a estabilidade dos agregados decresceu na medida em que aumentou a profundidade devido ao caráter coeso, tal como ocorreu um decréscimo do teor de matéria orgânica indicando que a matéria orgânica (Tabela 2) proporcionou maior estabilidade aos agregados, diferentemente do teor de argila, que aumentou com a profundidade (Tabela 1 ).

Com base na Tabela 3, o índice de estabilidade dos agregados (IEA) não sofreu, dos sistemas de manejo nem da interação sistemas de manejo x profundidade, qualquer influência. Esta situação está em acordo com Wendling et al. (2005) que, ao avaliarem os efeitos do manejo na estabilidade de agregados em água de um Latossolo Vermelho, não registraram diferenças significativas sobre a mesma variável.

Quanto ao módulo de finura de agregados (MF), não houve diferença significativa da interação manejo x profundidade, mas isoladamente os tipos de manejo exerceram efeitos significativos a nível de $5 \%$ de probabilidade, com superioridade do solo de mata sobre o manejo sem (MSI) e com irrigação (MCI), que não diferiram do solo fertirrigado com vinhaça - MCV (Tabela 3). Conforme verificado para o diâmetro médio ponderado (DMP) todos os tipos de manejo promoveram médias menores que no solo de mata, entretanto, não se registrou diferença estatística entre o manejo do solo fertirrigado com vinhaça (MCV) e o solo de mata nativa (MA), que continham os maiores teores de matéria orgânica em relação aos demais (Tabela 2). Rolim \& Freire (1997), trabalhando com doses de vinhaça sobre a estabilidade estrutural dos agregados do solo creditaram, à fração orgânica da vinhaça, o favorecimento da agregação do solo, o que também já havia sido evidenciado por Camargo et al. (1983).

O módulo de finura (MF) variou significativamente entre as profundidades de 0-20 e 40-60 cm; constatado para o DMP, mas diminuindo com a profundidade, assemelhando-se à tendência da matéria orgânica. Observa-se, a partir dos resultados, que os manejos promovem a degradação do solo ao longo do tempo, refletindo-se na diminuição da estabilidade dos agregados devido, em maior parte, aos efeitos da mecanização agrícola. Comparativamente, a tendência dos dados está compatível com Lacerda et al. (2005), ao constatarem que o manejo convencional do solo com grade aradora comprometeu os parâmetros DMG e IEA, comparados ao solo de mata.

Para o AGRI que considera os porcentuais superiores a 2,00 mm, as médias apresentaram resultados semelhantes as do DMP. Ou seja, houve diferença significativa entre os manejos e a condição MA, sendo que os manejos MSI e MCI foram os que apresentaram as maiores reduções dos agregados instáveis em água. Para a profundidade o AGRI acompanhou os demais indicadores DMP e o MF, apresentando tendência a diminuição com a profundidade, através da diferença estatística entre as médias nas profundidades entre 20-40 e 40-60 cm. 
As porcentagens da distribuição dos agregados estáveis em água por classe de diâmetro encontram-se na Figura 1. Observando-se os valores de agregados maiores que $3,25 \mathrm{~mm}$, na profundidade de $0-20 \mathrm{~cm}$, a maior distribuição ocorreu nas condições de MA e MCV, com 27,9 e 19,69\%, respectivamente, enquanto para MSI e MCI os valores foram 12,93 e $14,7 \%$, respectivamente. Para os agregados de diâmetro entre 3,35 e $2 \mathrm{~mm}$, os manejos apresentaram valores próximos aos encontrados na classe $>3,25 \mathrm{~mm}$ considerando, portanto, que as duas classes são maiores que $2,00 \mathrm{~mm}$ e os maio-
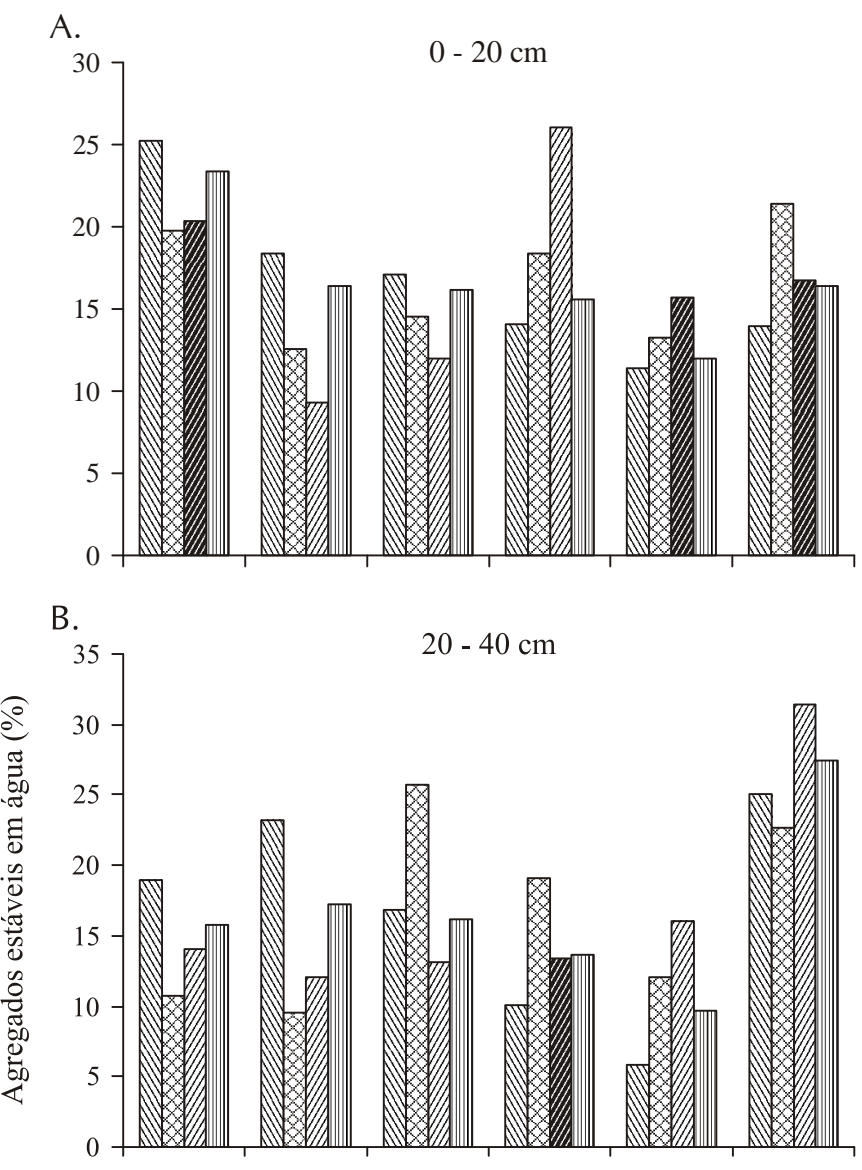

C.

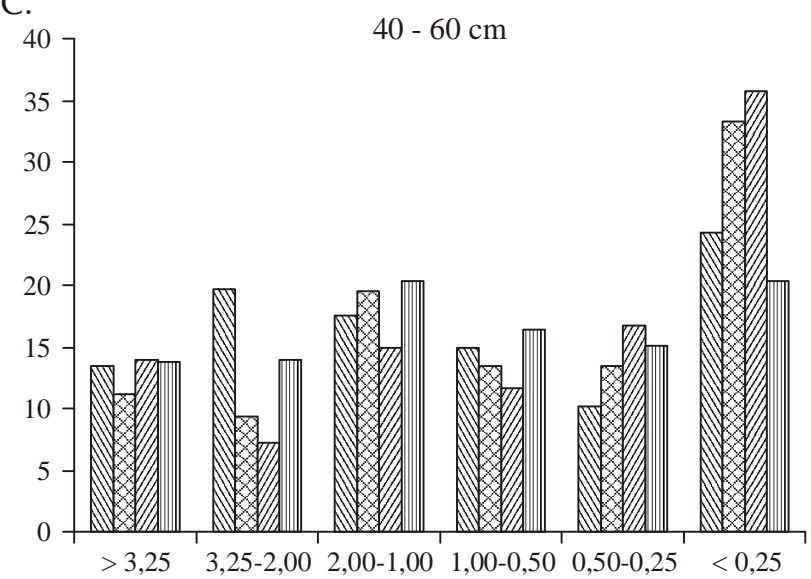

mata-MA 图 sequeiro-MSI $\mathbb{Z}$ irrigado-MCI 四 vinhaça-MCV

Figura 1. Distribuição dos agregados estáveis em água nas profundidades de $0-20$ (A); $20-40$ (B) e de 40-60 cm (C), para os quatro sistemas de manejo de solo estudados res porcentuais recaem nos manejos MA e MCV. Este comportamento comprova que em todos os manejos houve redução do tamanho de agregados em relação à mata nativa porém o manejo com vinhaça parece ter contribuído na maior manutenção do tamanho dos agregados; esses resultados corroboram com os encontrados por Silva (2003), quando trabalhou com tratamentos semelhantes.

Comparando-se os agregados de diâmetro entre 2,0 e $1,0 \mathrm{~mm}$ conclui-se que, praticamente, não houve variação com o manejo nesta profundidade, porém se nota, nas classes de 1,00 e 0,50 mm, e 0,50 e 0,25, que começa uma inversão em relação aos agregados $>2,00 \mathrm{~mm}$, ou seja, os manejos MSI e MCI apresentam valores maiores que os da MA e MCV, evidenciando a ação dos implementos de preparo convencional. Os resultados obtidos confirmam, mais uma vez, a observação de Carpenedo \& Mielniczuk (1990) de que os agregados se desagregam formando subagregados de tamanho menores. Para os microagregados $(<0,25 \mathrm{~mm})$, todos os manejos cultivados indicaram valores superiores aos encontrados na condição de MA.

Para a profundidade de $20-40 \mathrm{~cm}$ se constata, quando somadas as classes maiores que 2,0 mm, comportamento similar aos encontrados nas camadas de $0-20 \mathrm{~cm}$ e, para as classes entre 2,0 e 0,25 mm, o manejo sem irrigação (MSI) resultou nos maiores valores de agregados estáveis, fato explicado pela condição de menor umidade tendo em vista que neste manejo não é aplicado tipo algum de irrigação. Para os microagregados o comportamento da distribuição dos agregados dos manejos foi semelhante aos valores encontrados na profundidade de $0-20 \mathrm{~cm}$.

Na profundidade de 40-60 $\mathrm{cm}$ para as classes entre $>3,25$ e 3,25-2,00 mm, os maiores valores corresponderam ao solo de mata nativa (MA) e do solo fertirrigado com vinhaça (MCV). Entre as classes de 2,00 a 0,25 mm as diferenças porcentuais foram próximas enquanto para os microagregados $(<0,25 \mathrm{~mm})$ os manejos MSI e MCI mostraram os maiores porcentuais em relação aos demais.

Da mesma forma, ficou patente que nas condições estudadas o IEA não foi bom indicador de estabilidade de agregados, haja vista que não apresentou diferença estatística entre os manejos avaliados; quanto ao MF, que é mais utilizado para avaliar a estabilidade de agregados secos, também não se mostrou tratar-se de um bom indicador tendo em vista que não evidenciou a diferença entre os manejos MA e MCV, encontrada para as variáveis DMP e AGRI, respectivamente.

Pelas diferenças estatísticas ficou evidenciado que os valores médios de DMP, MF e AGRI, utilizados na avaliação dos

Tabela 4. Equações das correlações entre carbono orgânico total (COT) e os índices de agregação: diâmetro médio ponderado (DMP), índice de estabilidade de agregados (IEA), módulo de finura (MF) e porcentagem de agregados $>$ 2,00 mm estáveis em água (AGRI)

\begin{tabular}{ccc}
\hline Variáveis & Equações de correlações & $\mathbf{R}^{2}$ \\
DMP & DMP $=1,097+0,0378^{* *}$ COT & 0,866 \\
IEA & IEA $=69,048+0,1963^{\text {ns }}$ COT & 0,028 \\
MF & MF $=1,5306+0,0424 * *$ COT & 0,683 \\
AGRI & AGRI $=9,807+1,0736^{* *}$ COT & 0,768 \\
\hline
\end{tabular}

** significativo a $5 \%$ e $1 \%$, res pectivamente, pelo teste $t$ 

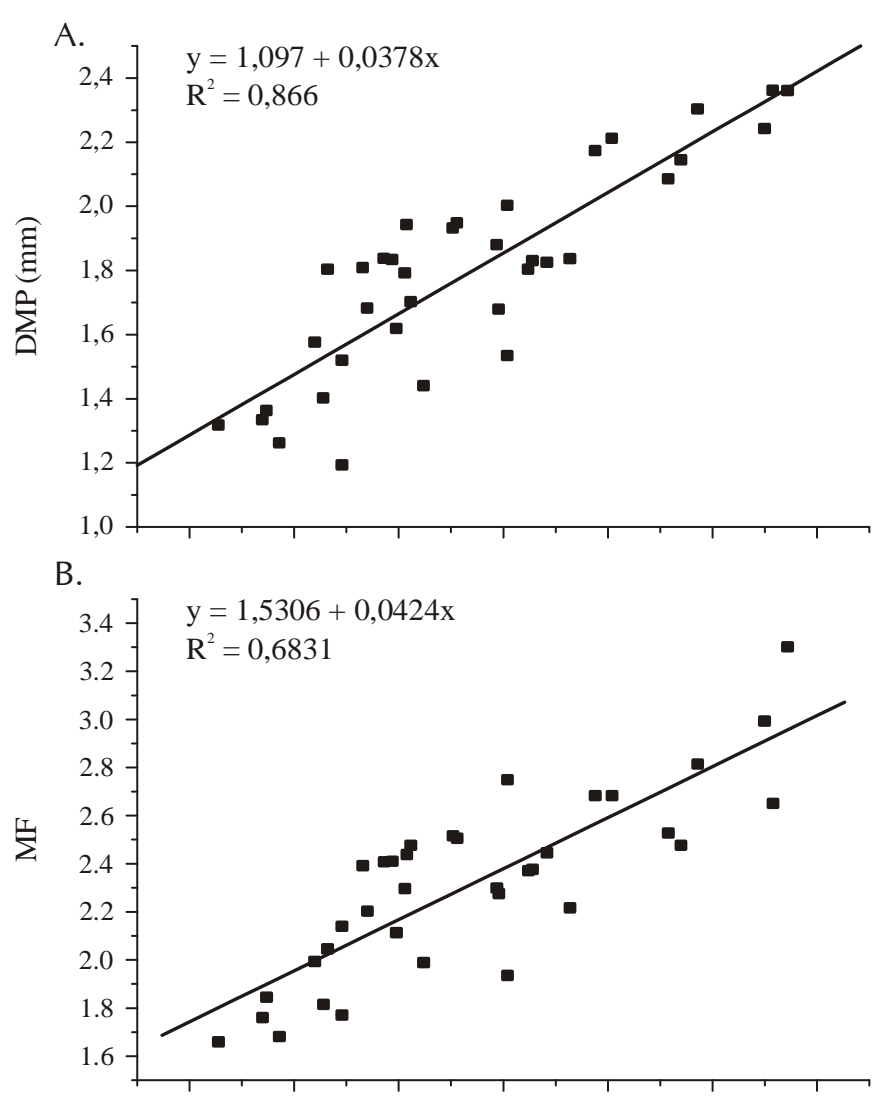

C.
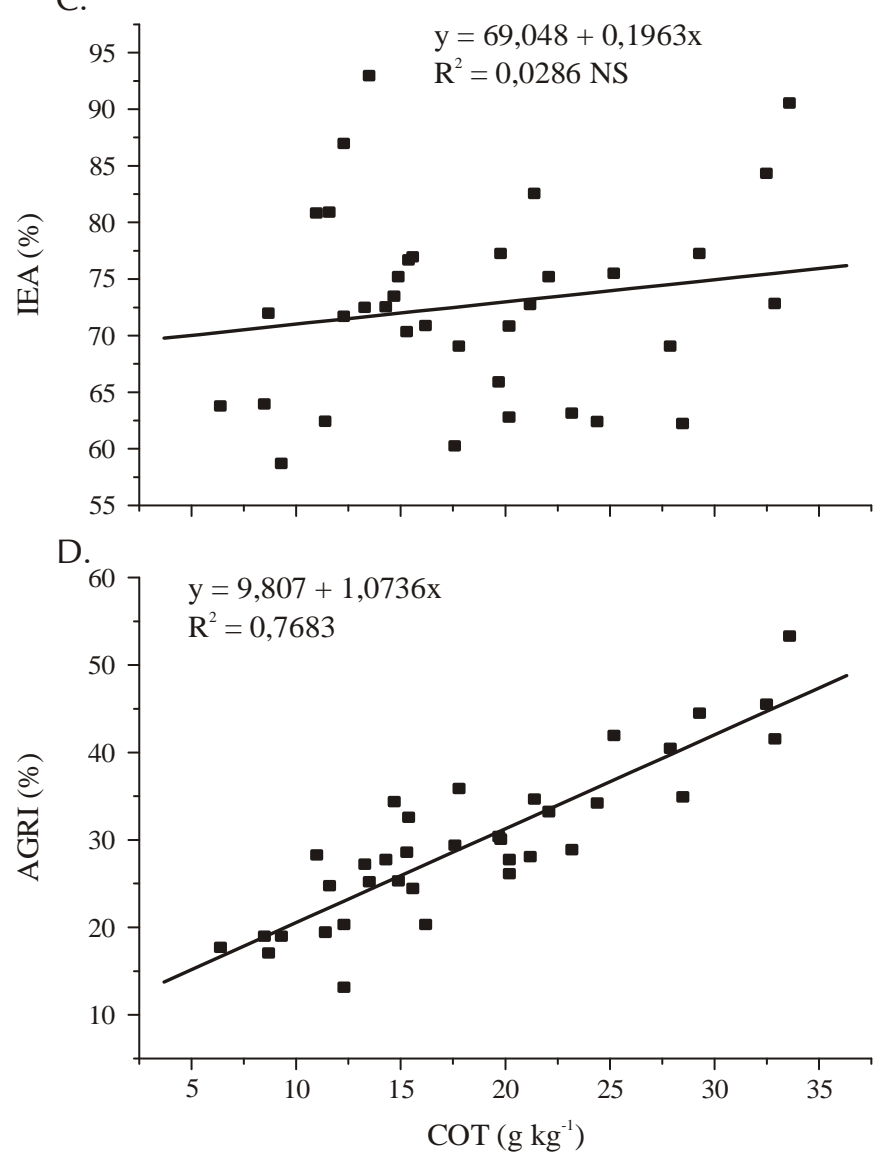

Figura 2. Relação entre o diâmetro média ponderado (DMP), índice de estabilidade de agregados (IEA), módulo de finura (MF), percentagem de agregados (AGRI) e o carbono orgânico total (COT) de um Argissolo Distrocoeso submetido a diferentes manejos, nas três profundidades $(0-60 \mathrm{~cm})$ agregados estáveis em água diminuíram com a profundidade do solo entre os tipos de manejo do solo sem irrigação e com irrigação devido ao menor teor de matéria orgânica nos horizontes inferiores, conforme se nota pelas correlações positivas entre os valores do carbono orgânico total (COT) e os indicadores da Tabela 4 e Figura 2, respectivamente.

Os coeficientes de correlação entre o COT com os valores dos índices de agregação (Tabela 4) foram positivos e significativos para DMP, MF E AGRI e não significativo para o IEA. Boas correlações também foram conseguidas por Paladini \& Mielniczuk (1991) e Palmeira et al. (1999), para o DMP. Castro Filho et al. (1998) encontraram altas correlações entre os índices de agregação DMP $(r=0,746)$, e IEA $(r=0,749)$ enquanto Wendling et al. (2005) avaliando o carbono orgânico e estabilidade de um Latossolo vermelho sob diferentes manejos, constataram correlações positivas e próximas às apresentadas na Tabela 4. Os mesmos autores atribuem a menor correlação do IEA com a matéria orgânica, ao fato de que o mesmo é calculado com base apenas na menor classe de agregados, que não é determinado por pesagem, mas por diferença e, ainda, que na menor classe não se englobam apenas agregados ou areia, mas também toda argila dispersa que perpassa pelas peneiras durante o processo de tamisamento, e que não se caracterizam como agregados; eles concluíram, então, que o IEA não é um parâmetro adequado para avaliar a estabilidade de agregados, porque é calculado com a proporção instável da amostra.

\section{CONCLUSÕES}

1. Ao longo do tempo, o cultivo da cana-de-açúcar, reduz a estabilidade de agregados do solo.

2. As variáveis percentagem de agregados $>2 \mathrm{~mm}$ (AGRI) estaveis em água e módulo de finura (MF) mostram-se eficazes como indicadores para avaliação da estabilidade de agregados.

3. O sistema de cultivo do solo com vinhaça (MCV) é que mais se aproxima da condição natural.

4. O carbono orgânico se correlaciona adequadamente com os valores de diâmetro médio ponderado (DMP), módulo de finura (MF) e percentagem de agregados > $2 \mathrm{~mm}$ (AGRI) estaveis em água na avaliação da estabilidade dos agregados do solo.

\section{LITERATURA CITADA}

Albuquerque, J. A.; Sangoi, L.; Ender, M. Efeitos da integração lavoura-pecuária nas propriedades físicas do solo e características da cultura do milho. Revista Brasileira de Ciência do Solo, v.25, p.717-723, 2001.

Araújo Filho, J. C.; Carvalho, J.; Silva, F. B. R. Investigações preliminares sobre a pedogênese de horizontes coesos dos tabuleiros do nordeste do Brasil. In: Workshop Coesão Em Solos dos Tabuleiros Costeiros, 2001. Aracaju. Anais... Aracaju: Embrapa Tabuleiros Costeiros, 2001, p.123-142. 
Baumgart, T. H.; Horn, R. Effect of aggregate stability on soil compaction. Soil \& Tillege Research, v.19, p.203-213, 1991.

Camargo, O. A.; Valadares, J. M. A. S.; Gerardi, R. N. Características químicas e físicas de um solo que recebeu vinhaça por longo tempo. Campinas: IAC, 1983. 30p. Boletim técnico, 76.

Cambardella, C. A.; Elliot, E. T. Carbon and nitrogen distribution in aggregates from cultivated and native grassland soils. Soil Science Society of America Journal, v.57, p.1071-1076, 1993.

Carpenedo, V.; Mielniczuk, J. Estado de agregação e qualidade de agregados de Latossolos Roxos, submetidos a diferentes sistemas de manejo. Revista Brasileira de Ciência do Solo, v.14, p.99-105, 1990.

Castro Filho, C.; Muzilli, O.; Podanoschi, A. L. Estabilidade dos agregados e sua relação com o teor de carbono orgânico em um Latossolo Roxo Distrófico, em função de sistemas de plantio, rotações de culturas e métodos de preparo das amostras. Revista Brasileira de Ciência do Solo, v.22, p.527-538, 1998.

COM - Commission of the European Communities. Communication from the Commission to the Council, the European Parliament, the Economic and Social Committee and the Committee of the Regions - Towards a thematic strategy for soil protection. Bruxelas: 2002. 35p.

Corrêa, J. C. Efeito de sistemas de cultivo na estabilidade de agregados de um Latossolo vermelho amarelo em Querência, MT. Pesquisa Agropecuária Brasileira, v.37, n.2, p.203-209, 2002.

Costa, F. S.; Bayer, C.; Albuquerque, J. A.; Fontoura, S. M. V. Aumento da matéria orgânica num Latossolo bruno em plantio direto. Ciência Rural, v.34, n.2, p.587-589, 2004.

EMBRAPA - Empresa Brasileira de Pesquisa Agropecuária. Centro Nacional de Pesquisa de Solos. Manual de métodos de análise de solo. Rio de Janeiro: Embrapa CNPS, 1997. 2.ed. 212p.

EMBRAPA - Empresa Brasileira de Pesquisa Agropecuária. Centro Nacional de Pesquisa de Solos. Sistema brasileiro de classificação de solos. Rio de Janeiro: Embrapa CNPS, 2006. 2.ed. 306p.

Fageria, N. K.; Stone, L. F. Qualidade do solo meio ambiente. Santo Antônio de Goiás: Embrapa Arroz e Feijão, 2006. 35p. Documento 197

Freire, W. J.; Piedade Jr., C. O módulo de finura dos agregados do solo como índice de estabilidade estrutural. Engenharia Agrícola, v.3, n.2, p.29-36, 1979.

Kemper, W. D.; Chepil, W. S. Size distribution of aggregates. In: Black,C.A.; Evans, D. D.; White, J. L.; Ensminger, L. E.; Clark, F. E. (ed.). Methods of soil analysis : physical and mineralogical propeties, including statistics of measurement and sampling. Part 1. Madison: American Society of Agronomy, 1965. 2.ed. p.499-510.

Kemper, W. D.; Rosenau, R. C. Aggregate stability and size distribution. In: Klute, A. (ed.). Methods of soil analysis. Madison: American Society of Agronomy, 1986. Part 1, p.425-442. Agronomy 9
Lacerda, N. B.; Zero, V. M.; Barilli, J.; Moraes M. H. Bicudo, S. J. Efeito de sistemas de manejo na estabilidade de agregados de um Nitossolo Vermelho. Engenharia Agrícola, v.25, n.3, p.686-695, 2005.

Maia, J. L. T.; Ribeiro, M. R. Propriedades de um Argissolo Amarelo fragipânico de Alagoas sob cultivo contínuo da cana-deaçúcar. Pesquisa Agropecuária Brasileira, v.39, p.79-87, 2004.

Marquez, C. O.; Garcia, V. J.;Cambardella,C. A.; Schultz, R. C.; Isenhart, T. M. Aggregate-size stability distribution and soil stability soil. Soil Science America Journal, v.68, p.725-735, 2004.

Olszevski, N.; Costa, L. M.; Fernandes Filho, E. I.; Ruiz, H. A.; Alvarenga, R. C.; Cruz, J. C. Morfologia de agregados do solo avaliada por meio de análise de imagens. Revista Brasileira de Ciência do Solo, v.28, p.901-909, 2004.

Paladini, F. C. S.; Mielniczuk, J. Distribuição de tamanho de agregados de um solo Podzólico Vermelho-Escuro afetado por sistemas de culturas. Revista Brasileira de Ciência do Solo, v.15, p.135-140, 1991.

Palmeira, P. R. T.; Pauletto, E. A.; Teixeira, C. F. A.; Gomes, A. S.; Silva, J. B. Agregação de um Planossolo submetido a diferentes sistemas de cultivo. Revista Brasileira de Ciência do Solo, v.23, p.189-195, 1999.

Rolim, M. M.; Freire, W. J. Efeito da vinhaça concentrada sobre a estabilidade estrutural dos agregados do solo. Engenharia Agrícola, v.16, n.3, p.69-76, 1997.

SAEG - Sistema para Análises Estatísticas, versão 9,0. Viçosa: Fundação Arthur Bernardes, 2005.

Silva, A. J. N. Alterações físicas e químicas de um Argissolo Amarelo Coeso sob diferentes sistemas de manejo com cana-de-açúcar. Porto Alegre: UFRGS, 2003. 120p. Tese Doutorado

Silva, A. J. N.; Cabeda, M. S. V.; Carvalho, F. G. Matéria orgânica e propriedades físicas de um Argissolo Amarelo Coeso sob sistema de manejo com cana-de-açúcar. Revista Brasileira de Engenharia Agrícola e Ambiental, v.10, n.3, p.579-585, 2006.

Silva, I. F.; Mielniczuk, J. Ação do sistema radicular de plantas na formação e estabilização de agregados do solo. Revista Brasileira de Ciência do Solo. v.20, p.113-117, 1998.

Six, J.; Elliot, E. T.; Paustian, K. Aggregate and organic matter dynamics under conventional and no tillage systems. Soil Science Society America Journal, v.63, p.1350-1358, 1999.

Soane, B. D. The role of organic matter in soil compactability: a review of some practical aspects. Soil Tillage Research, v.16, p.179-201, 1990.

Tisdall, J. M.; Oades, J. M. Organic matter and water-stable aggregates in soil. Journal of Soil Science, v.33, p.141-163, 1982.

Wendling, B.; Jucksch, I.; Mendonça E. S.; Neves, J. C. L. Carbono orgânico e estabilidade de agregados de um Latossolo Vermelho sob diferentes manejos. Pesquisa Agropecuária Brasileira, v.40, p.487-494, 2005. 